\title{
Correlation between rheological and mechanical properties of black PE100 compounds - Effect of carbon black masterbatch
}

\author{
G. Pircheraghi ${ }^{*}$, A. Sarafpour ${ }^{1}$, R. Rashedi ${ }^{2}$, K. Afzali ${ }^{2}$, M. Adibfar ${ }^{2}$ \\ ${ }^{1}$ Polymeric Materials Research Group (PMRG), Department of Materials Science and Engineering, Sharif University of \\ Technology, Tehran, Iran. \\ ${ }^{2}$ Research and Development Center, Jam Petrochemical Company, South Pars Special Economic Zone (Asalouyeh), Iran
}

Received 12 December 2016; accepted in revised form 1 March 2017

\begin{abstract}
Black PE100 compounds were prepared using a co-rotating twin screw extruder by addition of carbon black masterbatches containing 35-40 wt\% carbon black and different polymer carriers to a pipe grade PE100 material with bimodal molecular weight distribution. Different properties of carbon black masterbatches and PE100 black compounds were evaluated using thermal, rheological and mechanical tests. Rheological results indicated an inverse correlation between melt flow index (MFI) of masterbatch samples and storage modulus, complex viscosity and shear viscosity of black compounds, while flow instabilities of compounds were also postponed to higher shear rates. TGA indicated that masterbatch with highest value of MFI contained highest amount of low molecular weight lubricants which resulted in inhibition of strain hardening behavior in tensile test of its respective black compound unlike all other samples, reflecting possible suppressing of its long term resistance to slow crack growth. This behavior is attributable to facilitated crystallization and chain folding of longer chains in the presence of low molecular weight lubricants in this sample and consequently formation of thicker lamellas as confirmed by DSC, hence lowering density of entanglements in amorphous area and inhibition of strain hardening.
\end{abstract}

Keywords: rheology, PE100, carbon black, masterbatch, strain hardening

\section{Introduction}

Easy installation, cost effectiveness, long service life and excellent fatigue and corrosion resistance are among major features that have made polyethylene pipes the most suitable choice for gas and water distribution networks around the world for nearly 60 years [1]. PE pipes can be used for buried, above ground and marine installations which gives them great usage flexibility depending on the application they are intended for [1,2].

Among different variations of pipe grade polyethylene resins, like PE63, PE80 and PE100, the latter has the best properties and performance, especially in regard to long term creep resistance, owing this to its unique bimodal molecular weight distribution. This bimodal structure is usually produced in a specific double-reactor setup. In first reactor, low molecular weight polyethylene is produced in presence of high amount of $\mathrm{H}_{2}$ gas with no co-monomers. Subsequent$1 y$, in the second reactor and in presence of an $\alpha-$ olefin comonomer, polymerization of high molecular weight fraction occurs, producing long chains with controlled number of side branches and eventually a bimodal MWD. Schematic of molecular weight and comonomer distribution and respective molecular chain attributed to each molecular weight fraction in PE100 pipe material can be seen in Figure 1. Lower molecular weight chains tend to establish crystalline

"Corresponding author, e-mail: pircheraghi@sharif.edu (C) BME-PT 
parts in the microstructure given their shorter length, while higher molecular weight chains with side branches can establish tie molecules, linking crystalline lamellas together. Side branches also cause a disruption in crystallinity and hence lower the degree of crystallinity in the microstructure [3]. The fraction of low molecular weight chains is responsible for high stiffness and good processability while the higher molecular weight fraction with short chain branches yields increased creep resistance and mechanical properties by increasing density of inter-lamellar tie molecules [4-6].

Considering previous research regarding mechanical properties-microstructure relationship, strain hardening phenomenon is known to have a direct correlation with long term creep performance and resistance to slow crack growth (SCG) in polyethylene materials [7-9]. Recently, a correlation between structural and rheological properties of different bimodal polyethylene grades and environmental stress cracking resistance (ESCR) has been reported [8]. It has also been shown that the stereoregularity of the copolymer fraction of bimodal high-density polyethylene influences the environmental stress crack resistance [10]. Sun et al. [11] studied effect of molecular weight distribution on fracture behavior of bimodal PE materials and demonstrated that with increasing ratio of lower $M_{\mathrm{w}}$ fraction to higher $M_{\mathrm{w}}$ fraction, fracture toughness improves and also, the amount of thicker lamellas in structure increases without much change in total crystallinity of samples.

Studies have shown that long term exposure to UV radiation can negatively affect mechanical properties, alter polymer structure and initiate cracks in polyethylene structures [12-14]. The most widely used method for $\mathrm{UV}$ protection is producing black $\mathrm{PE}$ compounds by addition of $2-3 \%$ evenly dispersed carbon black, which significantly increases UV resistance

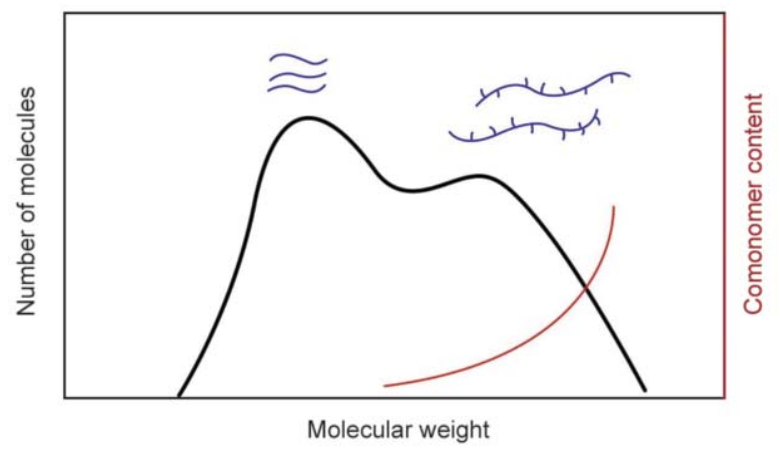

Figure 1. Schematic demonstrating molecular weight distribution in PE100 for an indefinite period of time $[1,15,16]$. An enough amount of right selected carbon black particles, with particle size of less than $20 \mathrm{~nm}$ [15] and good dispersion, can absorb almost all the UV radiation, preventing degradation of PE pipe material under sunlight for several years. Due to the polar nature of carbon black particles, existing concerns regarding its possible impacts on environment and health and also difficulties in transportation and handling of its powder, use of carbon black masterbatch has been preferred in the industry, using between 30-40 percent of carbon black in a PE-based masterbatch carrier. Carbon black masterbatches can be produced with different grades of carbon blacks and carriers employing different production methods, hence possibly affecting PE100 unique microstructure and outstanding mechanical properties.

In this study, different grades of carbon black masterbatch by different polymer carriers have been used to produce black PE100 compounds. Microstructure and properties of compounds have been studied using different tests such as microscopic images, thermal analysis, rheological and mechanical measurements. To the best knowledge of authors this is the first reported systematic investigation on effects of carbon black masterbatch on microstructural changes and properties of PE100 materials. Results of this research can be used for better insight into different factors affecting black compounds' performance and a criterion for effectively choosing the best masterbatch for production of black PE100 compounds.

\section{Experimental}

\subsection{Materials and sample preparation}

The bimodal PE100 powder was supplied by Jam Petrochemical Co., Iran, with the commercial name HMCRP $100 \mathrm{~N}\left(\rho=0.949 \mathrm{~g} / \mathrm{cm}^{3}, \mathrm{MFI}=0.3 \mathrm{~g} / 10 \mathrm{~min}\right.$, $190^{\circ} \mathrm{C}, 5 \mathrm{~kg}$ ). Three different grades of commercially available carbon black masterbatches containing $\sim 35-40 \mathrm{wt} \%$ carbon black were also provided by Jam Petrochemical Co. obtained from different suppliers. According to the supplier, all masterbatch samples should use HDPE as carrier and have p-type grade of carbon black. P-type is the purest grade of carbon black and has a particle size of 20-25 nm, excellent UV absorbance, contains a small amount of sulfur and toluene and is approved to be in contact with food products and potable water. The main difference between black masterbatches is their shape and carrier resin resulting in different flowabilities. 
Table 1. Carbon black masterbatches characteristics

\begin{tabular}{|c|l|c|c|c|}
\hline Masterbatch & Shape & $\begin{array}{c}\text { Carbon content } \\
{[\mathbf{\%}]}\end{array}$ & $\begin{array}{c}\mathbf{M F I}^{\mathbf{b}} \\
\mathbf{( 2 1 . 6} \mathbf{~ k g}, \mathbf{g} / \mathbf{1 0} \mathbf{~ m i n})\end{array}$ & $\begin{array}{c}\text { Bulk density }^{\mathbf{c}} \\
{\left[\mathbf{g} / \mathbf{c m}^{\mathbf{3}}\right]}\end{array}$ \\
\hline MK & Micro granule & 38.9 & 43.70 & 0.460 \\
\hline MP & Granule & 34.9 & 1.40 & 0.609 \\
\hline MR & Powder & 39.2 & 14.50 & 0.405 \\
\hline
\end{tabular}

${ }^{\mathrm{a}}$ Measured in lab based on TGA results, ${ }^{\mathrm{b}}$ Measured based on ASTM D1238, ${ }^{\mathrm{c}}$ Measured based on ASTM D1895

Table 2. PE100 compounds' formulations

\begin{tabular}{|l|c|c|c|c|}
\hline \multicolumn{1}{|c|}{ Sample code } & Masterbatch type & $\begin{array}{c}\text { PE100 powder } \\
{[\mathbf{w t} \mathbf{0}]}\end{array}$ & $\begin{array}{c}\text { Masterbatch } \\
{[\mathbf{w t} \% \mathbf{0}]}\end{array}$ & $\begin{array}{c}\text { Additives } \\
\text { (Antioxidants + lubricants) } \\
{[\mathbf{w t} \text { ] }]}\end{array}$ \\
\hline NPE100 & - & 99.50 & - & 0.5 \\
\hline PE100-MK & MK & 93.75 & 5.75 & 0.5 \\
\hline PE100-MR & MR & 93.75 & 5.75 & 0.5 \\
\hline PE100-MP & MP & 92.90 & 6.60 & 0.5 \\
\hline
\end{tabular}

Table 1 shows characteristics of used masterbatches. The PE100 black compounds were produced using a laboratory scale co-rotating twin screw extruder (JTE-32, $D=32 \mathrm{~mm}, l / d=40$, JIN SAN PRM, South Korea) with $180-200-220-210^{\circ} \mathrm{C}$ temperature profile form hopper to die and screw speed of $170 \mathrm{rpm}$. Before addition to the extruder, the PE100 powder, the masterbatch and the additives (including lubricants and antioxidants) were dry mixed very well to achieve desired dispersion. Sample codenames and their composition is presented in Table 2 .

\subsection{Characterizations}

Morphology of masterbatch particles and PE100 powder was investigated using optical microscope. Images were taken using a Nade NSZ-810 microscope. Apparent density of PE100 powder and masterbatch samples was measured based on ASTM D1895 standard test method which involves pouring sample's powder or granules to a cup through funnels with different opening diameters at their bottom depending on physical shape of samples.

Rheological properties of the masterbatches and prepared black compounds were measured in different flow fields using a Göttfert Reograph 25 instrument for capillary shear flow measurements and an Anton Paar MCR 502 instrument for oscillatory and rotational shear flow field at different temperatures. It is worth mentioning that oscillatory shear flow measurements were done in the linear viscoelastic region which was found based on preliminary amplitude sweep tests.

DSC analysis was performed using a TA Q100 (TA instruments, USA), with cooling and heating rates fixed at $10{ }^{\circ} \mathrm{C} / \mathrm{min}$ in 3 cycles to evaluate melting and crystallization points and degree of crystallinity. First cycle was performed to erase any thermal history from samples. TGA was performed using a Mettler Toledo TGA/DSC1 to evaluate carbon black content, thermal stability of compounds and presence of small molecules and lubricants in masterbatches.

For mechanical properties assessment, tensile test was performed using a Zwick/Roell (BT1-FR005TH.A50) at room temperature according to ASTM D638-08 with a strain rate of $50 \mathrm{~mm} / \mathrm{min}$. The reported results are average of at least 5 measurements.

\section{Results and discussion \\ 3.1. Characterization of carbon black masterbatches}

Figure 2a shows the morphology of the used masterbatches. Considering the huge throughput and hence very short residence time of extruders installed in petrochemical plants, the dry mixing of PE100 powder with carbon black masterbatch is very important. In other words, before melting and homogenization of components in twin extruder, carbon black masterbatch must be effectively distributed in the PE100 powder in pre-mixing dry blending stage. Therefore, for avoiding the segregation and achieving good blending, it is suggested that the bulk density and morphology of masterbatch and polyethylene powder must be similar [17-19]. As it is shown in Figure 2a and Table 1, MR and MK samples have irregular powder morphology and low bulk density of 0.405 and $0.460 \mathrm{~g} / \mathrm{cm}^{3}$ respectively, which facilitate their dry mixing with PE100 powder with bulk density of $0.431 \mathrm{~g} / \mathrm{cm}^{3}$. MP sample has granular morphology 
with bulk density of $0.609 \mathrm{~g} / \mathrm{cm}^{3}$, higher than the PE100 powder, leading to difficulties in its dry mixing and good distribution in polyethylene nascent powder. Based on these issues, the order of distribution of masterbatch samples in dry PE100 powder can be considered as follow: MK $\sim \mathrm{MR}>\mathrm{MP}$. The MK sample has more uniform morphology compared to MR sample, which can reduce the chance of uneven distribution of carbon black in final product. As can be seen in TGA results of different masterbatches, shown in Figure 2b, the carbon black content of masterbatches MK and MR is 38.9 and $39.2 \mathrm{wt} \%$ respectively and in good agreement with $40 \mathrm{wt} \%$ value reported by producers, while MP carbon black content is $34.9 \%$. It is generally accepted that with increasing of carbon black content in the masterbatch its dispersion in final black compound will be worsened. Moreover, the optimum value of carbon black content in black masterbatch used in the production of HDPE pipe compound is around

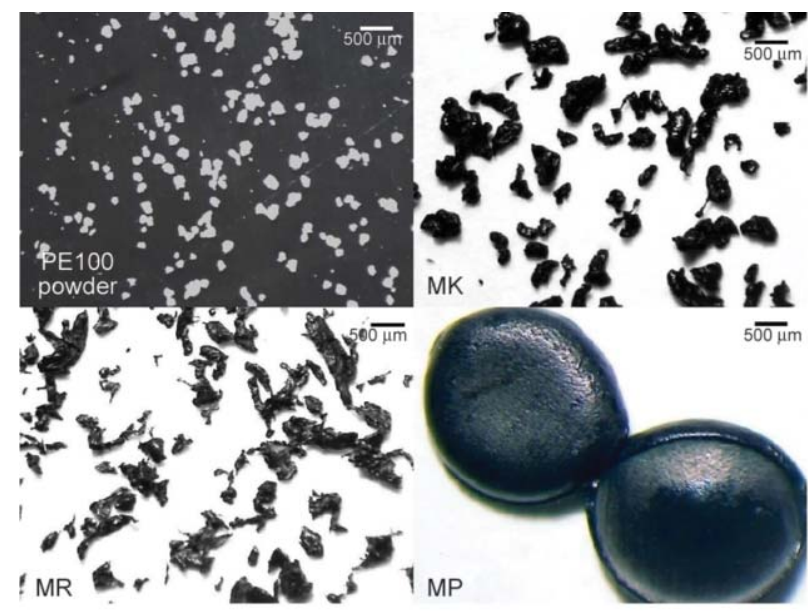

a)

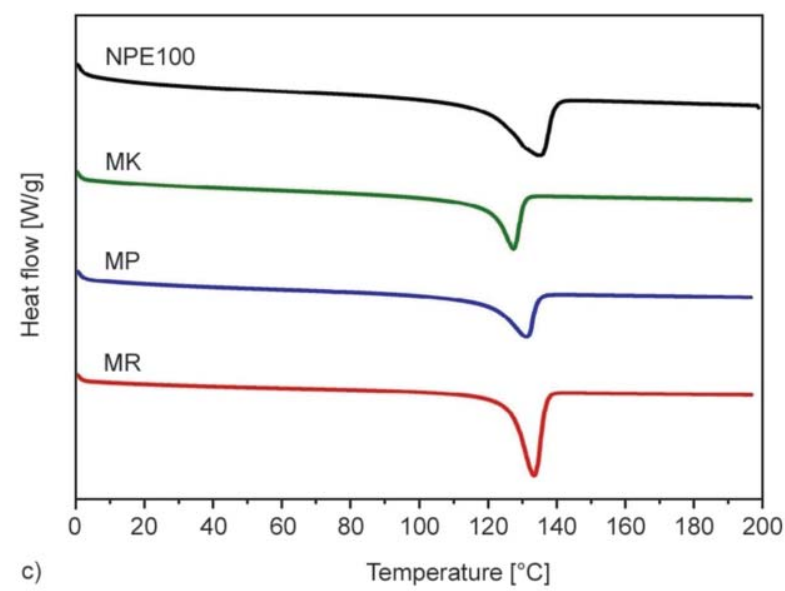

$40 \mathrm{wt} \%$ [20]. The lower carbon black content in masterbatch will result in better dispersion of carbon black in the compounds, but with the penalty of introducing the higher amount of masterbatch carrier leading to deterioration of the molecular weight balance and rheological properties especially in bimodal polyethylene resins.

Figure $2 b$ also shows the TGA results of masterbatch samples with different scales in the $25-500^{\circ} \mathrm{C}$ range. Thermal stability of all samples, the temperature in which sample loses $5 \%$ of its initial weight, is in the range $465-470^{\circ} \mathrm{C}$, indicating good thermal stability of samples during melt mixing process. However, the MK sample has the $T_{5 \%}=465^{\circ} \mathrm{C}$ while $T_{5 \%}$ of MR and MK samples is $\sim 470^{\circ} \mathrm{C}$. Moreover, the MK sample gradually lost $2 \%$ of its original weight before sharp reduction starting from $430^{\circ} \mathrm{C}$, pointing out presence of some low molecular weight lubricants in this sample, in agreement with its lower $T_{5 \%}$ compared to other samples. The presence of low molecular

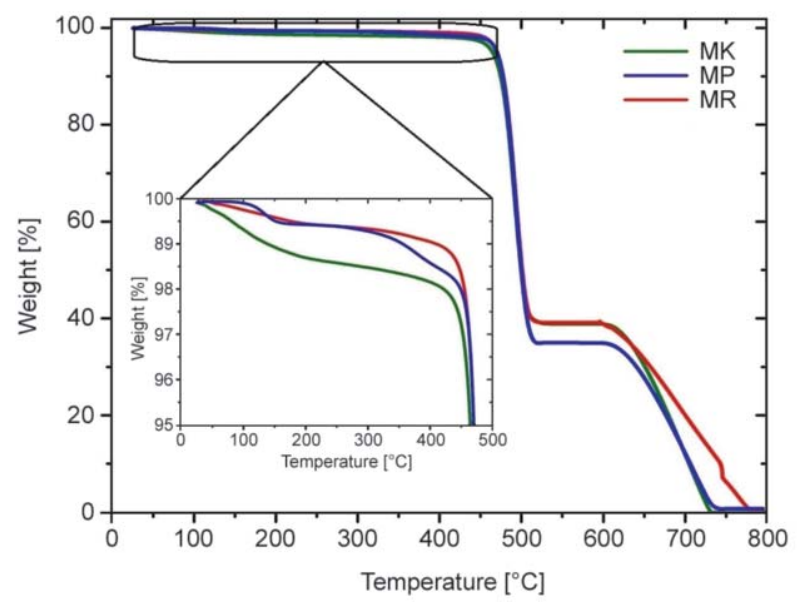

b)

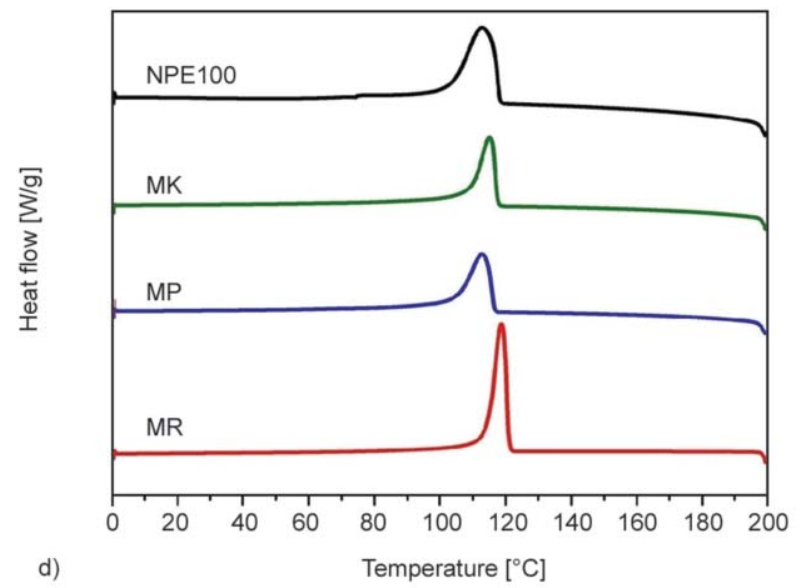

Figure 2. Masterbatch characterization: a) comparing particle size of masterbatch samples b) TGA results c) DSC heating cycle and d) DSC cooling cycle 
weight lubricants or PE wax can influence the rheological properties of black masterbatch and its corresponding black compound.

Using DSC results, shown in Figure $2 \mathrm{c}$ and 2d, one can recognize the masterbatch carrier type, considering the melting point of each sample. It is highly recommended to use a carrier with the potential of co-crystallization with PE100 matrix [21, 22]. Therefore, using the LDPE carrier due to its highly long chain branched molecules and hence its hindered cocrystallization [23] with the almost linear chains of PE100 should be avoided. As shown in Table 3, the melting point of masterbatches MP and MR are 131.2 and $133.4{ }^{\circ} \mathrm{C}$ respectively, pointing out the use of HDPE resins as masterbatch carrier, while MK masterbatch has a lower melting point of $127.4^{\circ} \mathrm{C}$, which might be indicative that LLDPE may also have been used as masterbatch carrier. Also, MR Masterbatch has nearly $40 \%$ more crystallinity compared to MP and MK and has also the highest crystallization and melting points, which may confirm use of specific HDPE with narrow molecular weight distribution and higher crystallinity as masterbatch carrier. Moreover, the masterbatch preparation method, as well as applied thermal and shear history during mixing the carbon black powder and masterbatch carrier, the

Table 3. Results and rheological parameters of masterbatch samples

\begin{tabular}{|l|c|c|c|c|c|}
\hline $\begin{array}{c}\text { Sample } \\
\text { code }\end{array}$ & $\begin{array}{c}\boldsymbol{T}_{\mathbf{m}} \\
{\left[{ }^{\circ} \mathbf{C}\right]}\end{array}$ & $\begin{array}{c}\boldsymbol{T}_{\mathbf{C}} \\
{\left[{ }^{\circ} \mathbf{C}\right]}\end{array}$ & $\begin{array}{c}\boldsymbol{X}_{\mathbf{C}} \\
{[\%]}\end{array}$ & $\boldsymbol{K}$ & $\boldsymbol{n}$ \\
\hline NPE100 & 131.4 & 116.2 & 50.2 & 56862 & 0.203 \\
\hline MK & 127.4 & 115.2 & 47.1 & 17943 & 0.424 \\
\hline MP & 131.2 & 112.8 & 47.6 & 142235 & 0.138 \\
\hline MR & 133.4 & 118.1 & 66.1 & 38504 & 0.367 \\
\hline
\end{tabular}

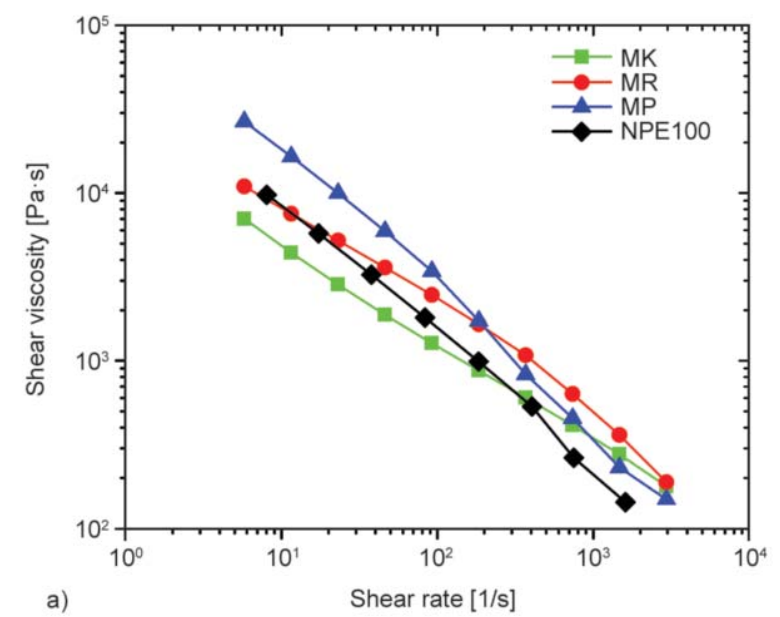

presence of carbon black and its surface chemistry can also change the crystallization behavior of masterbatch samples.

Figure 3a shows steady shear rheological properties of black masterbatch samples in comparison with NPE100 sample. It is well accepted that for melt miscibility and good mixing of polymeric materials, their rheological properties should be comparable [24, 25]. In other words, for better rheological miscibility, the flowability of masterbatch, containing 35-40 wt $\%$ carbon black, should be comparable with the polyethylene host resin. Among the used black masterbatches, MR sample shows shear viscosity very similar to base PE100 resin at 1-100 1/s shear rate range. But, at higher shear rates it cannot replicate the strong shear thinning behavior of neat PE100. MP sample shows very high viscosity at lower shear rates and its viscosity approaches to PE100 resin at high shear rates due to its strong shear thinning behavior mainly originated from its carrier resin molecular features. Moreover, MK sample shows the lowest shear viscosity, as shown in Figure 3a, among samples mainly due to use of higher amounts of lubricants/processing aids or use of low molecular weight LLDPE carrier resin. For more quantitative comparison, steady shear viscosity of masterbatch samples has been fitted in the Ostwald de Waele viscosity model (Equation (1)):

$$
\eta=K \cdot \dot{\gamma}^{\mathrm{n}-1}
$$

where $K$ is consistency constant, dependent to carbon black content, dispersion state and molecular weight of carrier resin, and $n$ is power law index

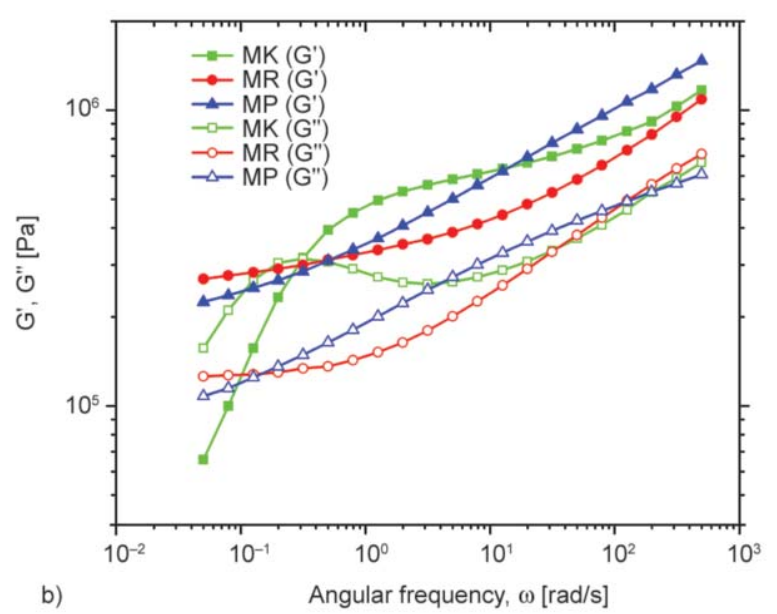

Figure 3. (a) Shear viscosity vs. shear rate behavior of masterbatch samples in comparison with natural PE100 measured at $190^{\circ} \mathrm{C}$ using a capillary rheometer, (b) storage and loss modulus of masterbatches samples measured at $190^{\circ} \mathrm{C}$ 
which is highly influenced with carrier resin shear thinning behavior owing to its molecular weight distribution and dispersion state of carbon black in masterbatch [26, 27]. Table 3 also shows rheological parameters, $K$ and $n$, of different masterbatches and NPE100 sample which are acquired by curve fitting of rheological results of the samples. Based on these results, one can quantitatively compare masterbatch samples. While $K$ values of MR and MK masterbatches are comparable with that of NPE100 compound, MP sample depicts a much higher $K$ value pointing out use of high molecular weight polyethylene resin, in line with its very low melt flow index at high load as reported in Table 1. However, MP sample has the closest power law index to NPE100 indicating using the masterbatch carrier with molecular weight distribution more similar to the neat PE100 resin.

Figure $3 \mathrm{~b}$ shows storage and loss moduli of masterbatch samples measured at $190^{\circ} \mathrm{C}$. While for MP and MR masterbatchtes the solid like behavior, $G^{\prime}>G^{\prime \prime}$, is observed in whole frequency range, because of formation of 3D network of carbon black and high molecular weight of carrier resin, MK sample shows liquid like behavior, $G^{\prime \prime}>G^{\prime}$, at low frequencies mainly due to presence of low molecular weight carrier and high content of lubricants, in line with TGA measurement and steady shear rheological results.

\subsection{PE100 black compounds characterization and discussion}

TGA test on the compounds also revealed, as expected, that PE100-MP had relatively lower amount of carbon black since its masterbatch, MP, was the same

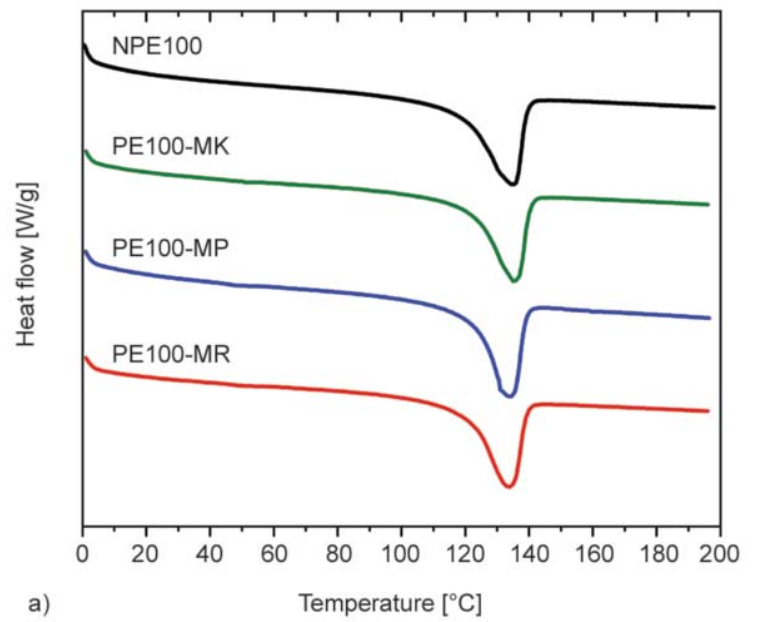

compared to two other masterbatch samples. Detailed results of carbon black dispersion evaluation and TGA for black compounds are presented in Supporting Information.

Figure 4 demonstrates DSC test results comparing black compounds with neat PE100 sample, NPE100. Melting and crystallization temperatures, degree of crystallinity, and average lamellae thickness, can be seen in Table 4. These microstructural features of semi crystalline materials are known to affect their mechanical and long term performance [28-30]. Lamellae thickness of samples was calculated using Gibbs-Thomson equation (Equation (2)):

$L=\frac{2 \sigma_{\mathrm{e}}}{\Delta H_{\mathrm{f}}\left(1-\frac{T_{\mathrm{m}}}{T_{\mathrm{m}}^{\circ}}\right)}$

where $L$ is average lamellae thickness, $\sigma_{\mathrm{e}}$ is lamellar surface energy, $\Delta H_{\mathrm{f}}$ is enthalpy of melting for a fully crystalline structure, $T_{\mathrm{m}}$ is melting point of the sample and $T_{\mathrm{m}}^{\circ}$ is melting point of an infinite crystalline structure. These values used to calculate lamellar thickness were $90 \mathrm{~mJ} \cdot \mathrm{m}^{-2}, 290 \mathrm{~J} \cdot \mathrm{cm}^{-3}, 418.8 \mathrm{~K}$ for $\sigma_{\mathrm{e}}, \Delta H_{\mathrm{f}}$ and $T_{\mathrm{m}}^{\circ}$ respectively [31]. The lamellar thickness calculated using Gibbs-Thomson equation can be good for mostly qualitative comparisons rather than obtaining exact values of lamellar thickness, since it is highly dependent on exact values of constants, like $T_{\mathrm{m}}^{\circ}$ and $\sigma_{\mathrm{e}}$, which may not be precisely calculated [31].

PE100-MK sample exhibits relatively higher melting point, correlating with the highest lamellae thickness among the samples. This might be attributable to existence of low molecular weight lubricants in MK

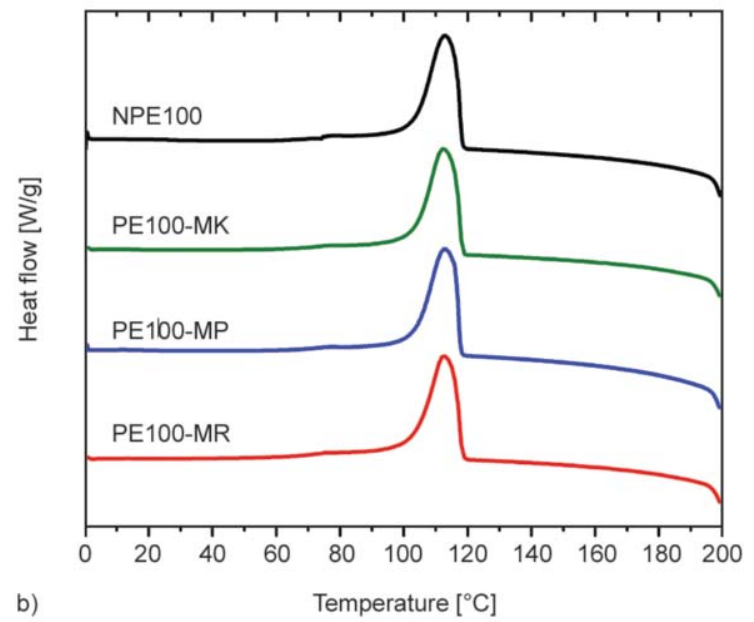

Figure 4. DSC thermographs of black compounds and NPE100 sample; a) heating cycle and b) cooling cycle 
masterbatch that in turn facilitate folding of long chains and lamellar growth leading to thicker lamellas and hence, higher melting point [4]. As it is expected, crystalline degree of black compounds is lower than neat sample mainly due to hindrance effect of carbon black aggregates and different potential of carrier polymer for co-crystallization with PE100 chains.

It is well accepted that rheological materials functions are highly sensitive to molecular features and hence can be used for better understanding about the relationship between the microstructure and properties of polymeric samples [4, 32, 33]. Moreover, rheological measurements reflect the processability and viscoelastic phenomena, such as flow instability or melt fracture, which may occur during melt processing of prepared samples [34, 35]. Figure 5a shows complex viscosity vs. frequency of compounds reflecting the influence of masterbatch carrier on rheological properties of black compounds. While, complex viscosity of PE100-MR is comparable with NPE100, the PE100-MK shows decreased complex viscosity and PE100-MP sample presents increased complex viscosity compared to NPE100 in the whole frequency range, in line with the melt flow rate of masterbatch samples. Figure 5 b shows storage modulus vs. frequency of samples measured at linear viscoelastic region. Herein, a similar trend to the complex viscosity changes is observed, the highest storage modulus is obtained in the sample (PE100-MP) compounded with the lowest melt flowable masterbatch (MP sample) and vice versa. These results clearly show the important role of masterbatch carrier on rheological properties and processability of black PE100 compounds. The wrong selection of masterbatch will result in disrupted rheological properties of final black compounds, leading to serious processing problems in pipe production such as sagging, melt fracture, surface roughness, high melt pressure and low throughput. Therefore, it is expected that PE100-MK compound, instead of its well dispersed carbon black, exhibits high sagging during processing the large and high pressure polyethylene pipes due to its reduced melt viscosity, while polyethylene pipe produced with PE100-MP may suffer from high surface roughness originating form flow instabilities and melt fracture occurred in high melt viscosity compounds as well as low throughput.

One may consider that rheological properties of PE100-MR are exactly similar to NPE100 according to results presented in Figures $5 \mathrm{a}$ and $5 \mathrm{~b}$ reflecting the same microstructure for two samples. This is, however, not true, because with the addition of about $6.5 \mathrm{wt} \%$ masterbatch to neat bimodal PE100 resin, the original molecular weight distribution will be changed in the black compound, but it seems that the complex viscosity and storage modulus which are measured at small amplitude oscillatory shear are not sensitive enough to slight changes in the microstructure of this sample.

Figure $5 \mathrm{c}$ shows shear viscosity vs. shear rate for different samples measured using parallel plate geometry at $190^{\circ} \mathrm{C}$ at low shear rate region and Figure $5 \mathrm{~d}$ presents shear viscosity measured at high shear rates using a capillary rheometer. The shear thinning behavior is observed in both shear rate regions, while at very high shear rates region, $1000 \mathrm{1} / \mathrm{s}$, shear viscosity of all samples approaches the same value due to pronounced disentanglements and orientation of long polymer chains. In other words, at high shear rates, in the non-linear viscoelastic region, the steady shear rheological properties of samples are controlled by PE100 matrix. On the other hand, the rheological properties at very low shear rates, $0.01-11 / \mathrm{s}$ range, are not very sensitive to slight change in the microstructure of sample because of the same shear viscosity measured for PE100-MR and NPE100 samples. Interestingly, the steady shear response at medium shear rates, $\sim 10-100 \mathrm{l} / \mathrm{s}$ region, is very sensitive to the microstructure of samples as results shown in Figure 5d. Herein, it is worth mentioning that a similar trend to the complex viscosity is observed for shear viscosity at low shear rates. Moreover, the PE100-MK sample shows the lowest shear viscosity in all shear rates pointing out use of lubricants and low molecular weight carrier in this sample, while PE100-MP sample exhibits the highest shear viscosity in whole shear rate range in line with its non-flowable used masterbatch, MP sample. The shear viscosity of PE100-MR sample is similar to the neat PE100 sample at low and high shear rates, while its shear viscosity is higher than the NPE100 sample at medium shear rates. Therefore, as it was expected, molecular features of PE100-MR compound is not the same as NPE100 sample.

For more quantitative evaluation of results, the shear viscosity of samples at low shear rates has been fitted to Carreau-Yasuda model, Equation (3), and results are presented in Table 4: 

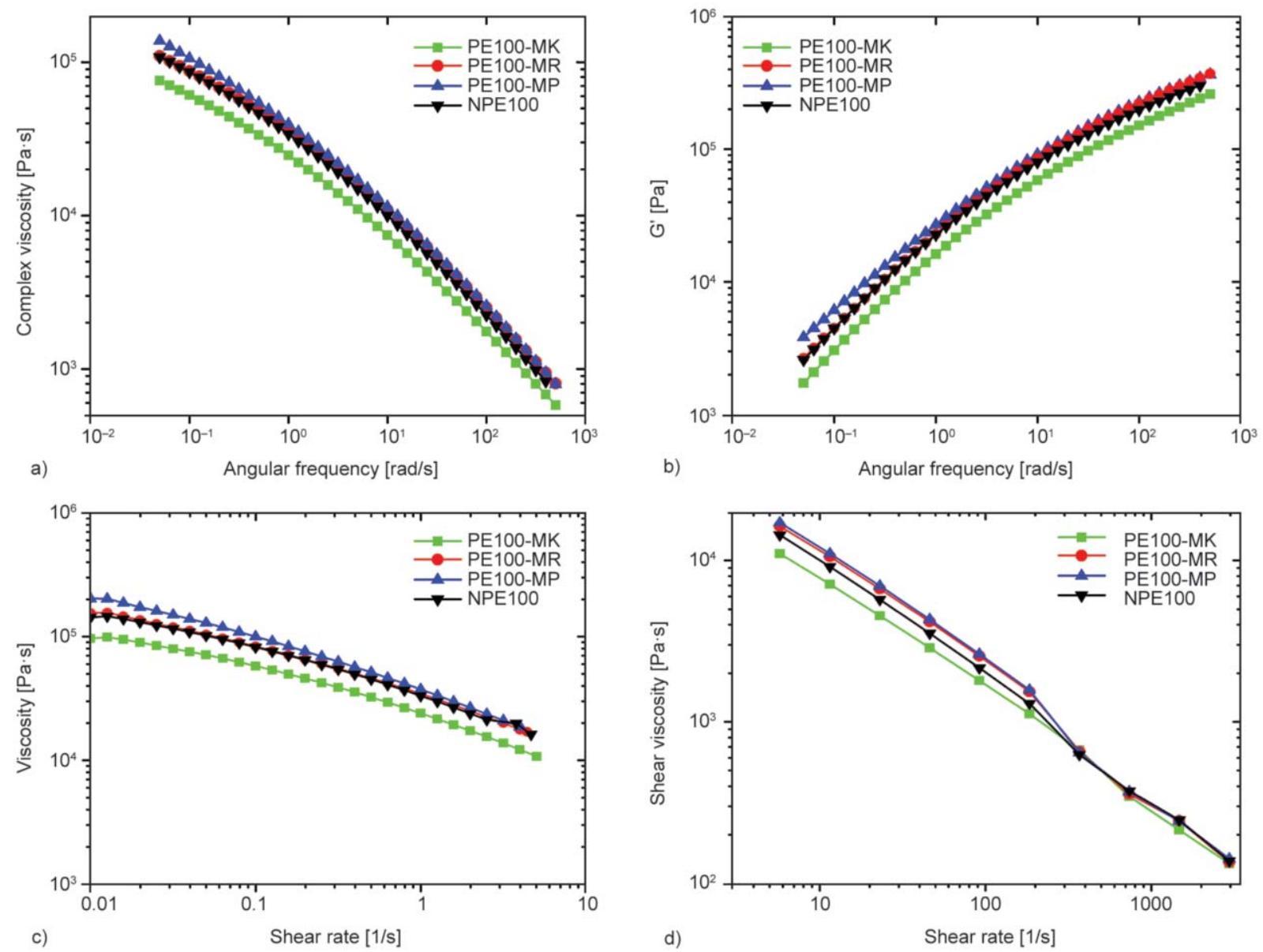

Figure 5. a) Complex viscosity vs. frequency, b) storage modulus vs. frequency (c) viscosity vs. shear rate in rotational shear flow field using parallel plate geometry and d) shear viscosity vs. shear rate with capillary shear flow field using capillary rheometer

$$
\eta(\dot{\gamma})=\eta_{\infty}+\left(\eta_{0}-\eta_{\infty}\right)\left[1+(\lambda \dot{\gamma})^{\mathrm{a}}\right]^{\frac{\mathrm{n}-1}{\mathrm{a}}}
$$

where, $\eta_{\infty}, \eta_{0}, \lambda$ and $n$ are infinite and zero shear viscosity, relaxation time and shear thinning or powerlaw index respectively and $a$ is a parameter influenced with the size and curvature of the crossover region between the Newtonian and shear-thinning behavior [36]. Considering $\eta_{\infty}=0$, parameters of Carreau-Yasuda model were calculated using RHEOPLUS/32 V3.6 rheology software and shown in Table 4. It is worth mentioning that for $\dot{\gamma}<\lambda^{-1}$, the Carreau-Yasuda fluid behaves as a Newtonian fluid with constant viscosity of $\eta_{0}$. Moreover, for high shear rates, $\lambda \dot{\gamma} \gg 1$, the Carreau-Yasuda model can be simplified to Ostwald-de Waele or power-law model. Values of steady shear viscosity vs. shear rate of black compounds (Figure 5d) at medium shear rate, 3$300 \mathrm{1} / \mathrm{s}$, were also fitted into Ostwald-de Waele model (Equation (1)) and values of $K$ and $n$ can also be seen in Table 4 for comparison.

Based on the results shown in Table 4, the relaxation time, and zero shear viscosity are decreased in PE100MK black compound compared to neat sample, NPE100, indicating the suppression of chain entanglements due to presence of small polymeric chains and lubricants. On the other hand, the highest zero

Table 4. Melting and crystallization points, degree of crystallinity and rheological properties for black compounds and NPE100 sample

\begin{tabular}{|l|c|c|c|c|c|c|c|c|c|c|}
\hline \multicolumn{1}{|c|}{ Sample } & $\begin{array}{c}\boldsymbol{T}_{\mathbf{m}} \\
{\left[{ }^{\circ} \mathbf{C}\right]}\end{array}$ & $\begin{array}{c}\boldsymbol{T}_{\mathbf{C}} \\
{\left[{ }^{\circ} \mathbf{C}\right]}\end{array}$ & $\begin{array}{c}\boldsymbol{X}_{\mathbf{C}} \\
{[\mathbf{\%}]}\end{array}$ & $\begin{array}{c}\text { Lamellae thickness } \\
{[\mathbf{n m}]}\end{array}$ & $\begin{array}{c}\boldsymbol{K} \\
(\text { Power law) }\end{array}$ & $\begin{array}{c}\boldsymbol{n} \\
(\text { Power law) }\end{array}$ & $\begin{array}{c}\boldsymbol{\eta}_{\mathbf{0}} \\
{[\mathbf{P a} \cdot \mathbf{s}]}\end{array}$ & $\begin{array}{c}\boldsymbol{\lambda} \\
{[\mathbf{s}]}\end{array}$ & $\boldsymbol{n}$ & $\boldsymbol{a}$ \\
\hline NPE100 & 134.1 & 113.0 & 50.2 & 22.8 & 49636 & 0.301 & 206120 & 42.11 & 0.53 & 0.65 \\
\hline PE100-MK & 135.0 & 112.2 & 45.0 & 24.7 & 35626 & 0.340 & 122620 & 32.70 & 0.54 & 0.77 \\
\hline PE100-MP & 133.9 & 112.9 & 45.0 & 22.4 & 62759 & 0.299 & 461530 & 71.21 & 0.45 & 0.42 \\
\hline PE100-MR & 133.0 & 112.7 & 44.9 & 20.8 & 55281 & 0.319 & 340010 & 60.50 & 0.50 & 0.40 \\
\hline
\end{tabular}


shear viscosity and relaxation time is observed in PE100-MP sample pointing out that high restriction in movement of chains may be due to pronounced entanglements and polymer-carbon black interaction in this sample. Interestingly, PE100-MP sample shows the highest shear thinning behavior in low and medium shear rates, among the samples because of sharp reduction in viscosity after disentanglement and orientation of long chains. Furthermore, the results reported in Table 4, clearly and quantitatively demonstrate the different rheological behavior of PE100MR sample compared to the NPE100 sample. These results tell us how rheological measurements is sensitive to small microstructural changes in black sample caused by carbon black-polymer as well as chainchain interactions due to difference in rheological and molecular features of base PE100 resin and masterbatch carrier. Among the rheological parameters reported in Table 4, parameter $a$ can be attributed to molecular weight distribution of samples which control the Newtonian length. It is obvious that how this

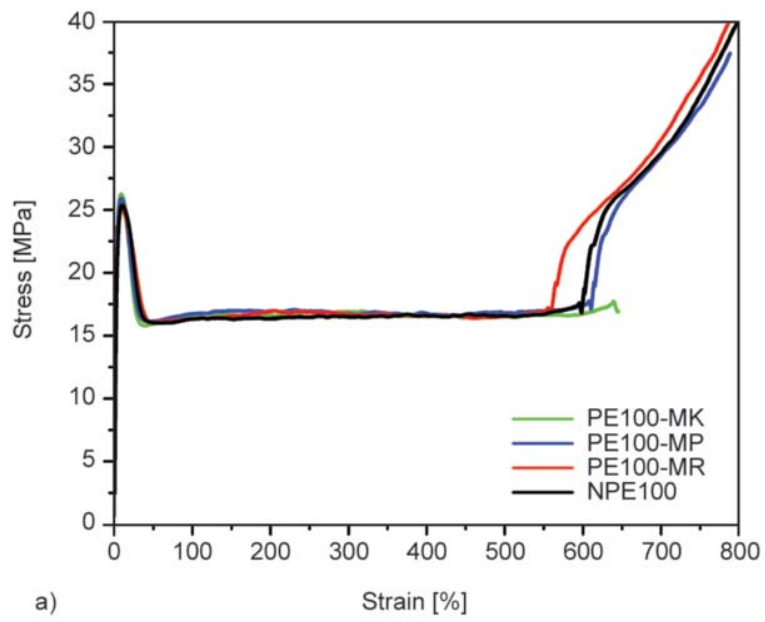

parameter is also influenced by the type of masterbatch in black sample. In other words, based on these results molecular weight distribution of black samples is influenced with addition of carbon black carrier and definitively is not the same as that of NPE100 sample.

Considering the important role of chain entanglements, reflected in enhanced zero shear viscosity and relaxation time in melt state, on slow crack growth (SCG) resistance, these results can be used as quantitative criteria for finding the proper masterbatch for production of black PE100 compounds.

\subsection{Mechanical properties}

Figure 6a shows complete stress-strain curves of black samples and NPE100. In this figure, it can be seen that except for PE100-MK sample, all others have the 4 different areas of elastic behavior, strain softening, cold draw and strain hardening. Looking at stress-strain curve, an interesting observation in tensile behavior of PE100-MK sample is seen. This
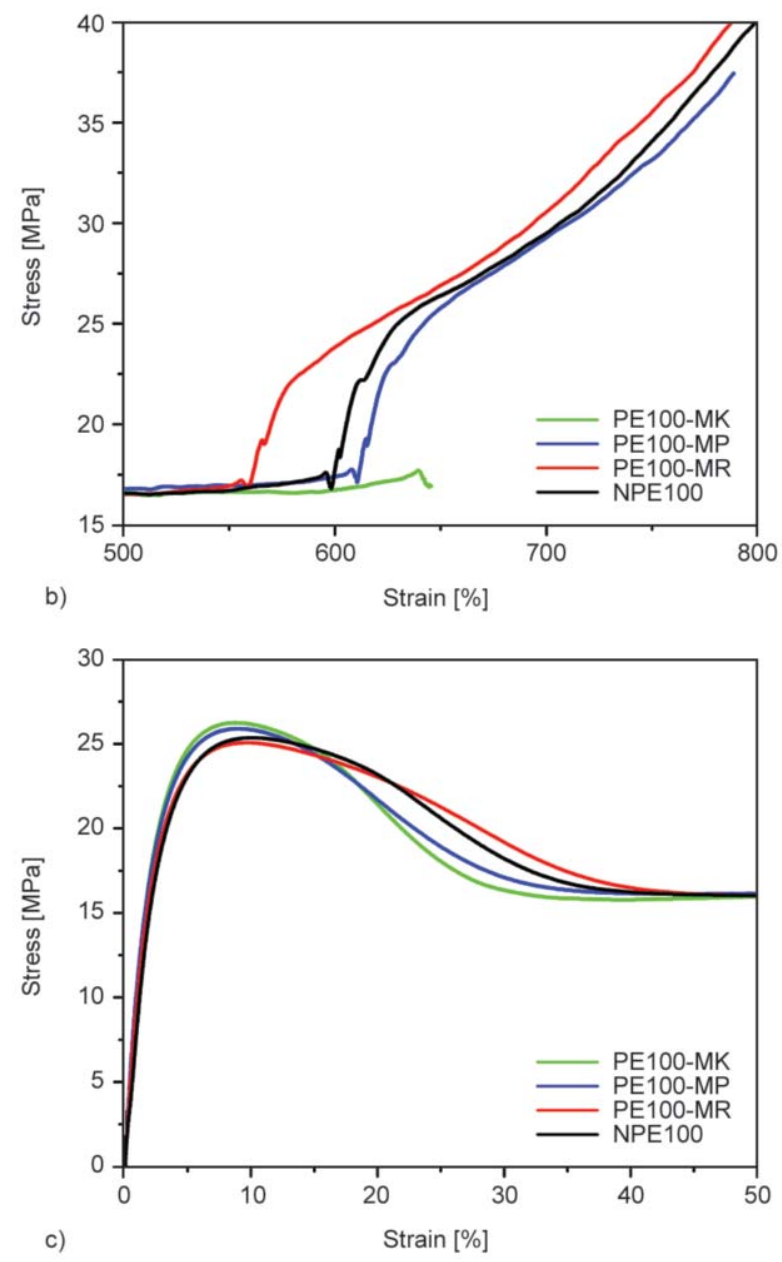

Figure 6. Stress-Strain curve of the black compounds and NPE100, (a) complete stress-strain curve (b) strain hardening and (c) elastic region and stress softening section 
sample exhibits largest elastic modulus and yield strength, shown in Table 5, while it doesn't have strain hardening after cold draw region as seen in Figure $6 \mathrm{~b}$. This behavior was repeated for all 5 PE100MK samples. MK masterbatch has some lubricants and short chains as shown in its TGA results. Also, rheological measurements of MK masterbatch and its compound, PE100-MK, confirmed this as they showed highest amount of MFI values and lowest amount of zero shear viscosity and relaxation time obtained from Carreau-Yasuda model as well as the lowest $K$ constant in power law model. It is also important to note that PE100-MK sample had the highest melting point which demonstrates a higher average lamellae thickness calculated using GibbsThomson equation. This can be indicative that folding of higher molecular weight chains in crystalline lamellas is facilitated because of existing lubricants and lower molecular weight chains in MK masterbatch. Sun et al. [11] and Wu et al. [4] showed that the number of thicker lamellas can be increased by increasing lower molecular weight fraction in bimodal PE materials while total crystallinity remains the same, which explains higher average lamellar thickness in PE100-MK. On the other hand, this facilitated chain folding of high molecular weight molecules in thick lamellas can lead to lower number of long chains tie-molecules in amorphous region and subsequently decreased chain entanglements in interlamellar areas, effectively obstructing demonstration of strain hardening as it is believed that strain hardening is directly correlated with density of chain entanglements [37]. As can be seen in Table 5 and Figure 6c, PE100-MK exhibits highest tensile modulus while NPE100 has the lowest, but as Cheng et al. [9] demonstrated, resistance to slow crack growth is not proved to be correlated with yield strength of the material.

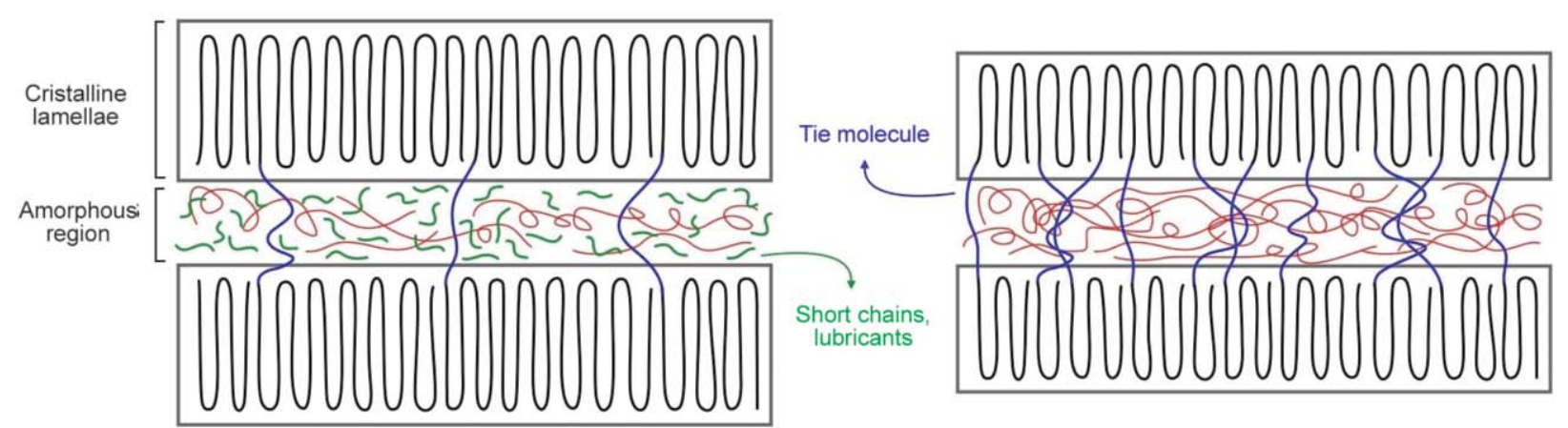

a)

b)

Figure 7 shows a schematic of lamellas and amorphous region between them compared for PE100-MK and three other samples, i.e. NPE100, PE100-MP and PE100-MR which have similar crystalline properties. As it can be seen in this figure, PE100-MK sample has relatively thicker lamellas, while its amorphous region is lacking in terms of existence of long chain tie-molecules and hence, decreased density of chain entanglements. Also high amounts of short chains and small molecules can be assumed in its inter-lamellar area. Therefore, it is reasonable to assume that density of tie-molecules is lower in this sample at solid state, in part due to facilitated chain folding of longer chains in thick lamellas and less chance for them act as tie molecules. The opposite is true for three other samples, which is lower thickness of lamellas, higher amount of tie molecules and higher chain entanglements in amorphous region.

Kurelec et al. [7] demonstrated direct correlation between strain hardening modulus measured at $80^{\circ} \mathrm{C}$ and ESCR, since they believed that difference in tensile behavior of samples was not sensitive at room temperature and high strain rates. But Cheng et al. [9] showed that ESCR correlation with strain hardening can be extended to room temperature and higher strain rates. It is important to note that insensitivity of strain hardening modulus differences measured at room temperatures cannot be an issue in this study, because PE100-MK sample didn't have any strain hardening at all, while three other samples did exhibit it, including NPE100. So it can be concluded that PE100-MK sample can be ranked as worst sample in terms of resistance to possible long term failures and resistance to slow crack growth. Another issue that should be stressed again is that lack of strain hardening in PE100-MK sample is solely related to addition of $5.75 \%$ of MK carbon black masterbatch to a PE100 pipe grade material that is meant to have

Figure 7. Schematics comparing lamellas and amorphous region of a) PE100-MK with b) NPE100, PE100-MP and PE100-MR 
Table 5. Mechanical properties of black compounds in comparison with natural PE100 resin

\begin{tabular}{|l|c|c|c|c|c|}
\hline \multicolumn{1}{|c|}{ Sample } & $\begin{array}{c}\text { Yield strain } \\
{[\mathbf{M P a}]}\end{array}$ & $\begin{array}{c}\text { Young modulus } \\
{[\mathbf{M P a}]}\end{array}$ & $\begin{array}{c}\text { Yield strength } \\
{[\mathbf{M P a}]}\end{array}$ & $\begin{array}{c}\text { Break stress } \\
{[\mathbf{M P a}]}\end{array}$ & $\begin{array}{c}\text { Elongation } \\
{[\%]}\end{array}$ \\
\hline NPE100 & $25.2 \pm 0.6$ & $1172 \pm 93$ & $10.2 \pm 0.5$ & $35.1 \pm 0.6$ & $736 \pm 8$ \\
\hline PE100-MK & $26.8 \pm 0.6$ & $1293 \pm 151$ & $9.2 \pm 0.6$ & $19.4 \pm 3.6$ & $586 \pm 80$ \\
\hline PE100-MR & $24.5 \pm 0.3$ & $1244 \pm 124$ & $9.8 \pm 0.4$ & $35.1 \pm 4.2$ & $736 \pm 39$ \\
\hline PE100-MP & $25.5 \pm 0.5$ & $1267 \pm 186$ & $9.6 \pm 0.5$ & $35.6 \pm 3.5$ & $768 \pm 18$ \\
\hline
\end{tabular}

good resistance to creep and SCG. Finally, it should be noted that although various studies have been conducted on mechanical performance of different polyethylene grades $[4,7-9,28,29,32,38-40]$, there have been no previous studies to solely focus on effect of adding carbon black masterbatches on pipe grade PE materials.

\section{Conclusions}

A right selection of carbon black masterbatch for producing black PE100 compound is an important issue, because black compounds of PE pipes are produced in massive industrial scales and wrong selection of a masterbatch can unexpectedly suppress outstanding properties of PE100 pipe material especially its good creep performance. Therefore, in this work, it was attempted to evaluate effect of adding different grades of commercially available carbon black masterbatch on a PE100 pipe material by means of optical, rheological, thermal and mechanical tests. It was observed that melt flow index of masterbatch sample has an inverse relationship with storage modulus, complex viscosity, shear viscosity and relaxation time of black compound. Also, black compound whose respective masterbatch had highest amount of low molecular weight chains, as indicated by TGA and rheological measurements, demonstrated no strain hardening in its tensile test. This behavior can be rationalized by saying that small molecules in this sample can facilitate the crystallization process, hence making longer chains to contribute in formation of thicker lamellas, which in turn, can decrease their chance of acting as inter-lamellar tie molecules and also, lower chain entanglements in amorphous area. This is a matter of importance because strain hardening is directly correlated with long term creep performance of PE material. Eventually, this study presents some complementary criterion for selection of right black masterbatch for production of PE100 black compounds with preserved outstanding properties of neat materials and also opens a new scope in regards to correlating addition of carbon black masterbatch to PE100 with various thermal, rheological and mechanical characteristics of the compound, something that has rarely been discussed in previous studies.

\section{Acknowledgements}

The financial support of this project provided by Jam Petrochemical Company is highly acknowledged.

\section{References}

[1] The Plastics Pipe Institute: Handbook of polyethylene pipe. Plastics Pipe Institute, Irving (2006).

[2] Peacock A.: Handbook of polyethylene: Structures, properties and applications. Taylor \& Francis, New York (2000).

[3] Brömstrup H.: PE 100 pipe systems. Vulkan-Verlag, Essen (2004).

[4] Wu T., Yu L., Cao Y., Yang F., Xiang M.: Effect of molecular weight distribution on rheological, crystallization and mechanical properties of polyethylene- 100 pipe resins. Journal of Polymer Research, 20, 271/1271/10 (2013).

https://doi.org/10.1007/s10965-013-0271-9

[5] Hubert L., David L., Seguéla R., Vigier G., Degoulet C., Germain Y.: Physical and mechanical properties of polyethylene for pipes in relation to molecular architecture. I. Microstructure and crystallisation kinetics. Polymer, 42, 8425-8434 (2001). https://dx.doi.org/10.1016/S0032-3861(01)00351-2

[6] Alt F. P., Böhm L. L., Enderle H-F., Berthold J.: Bimodal polyethylene - Interplay of catalyst and process. Macromolecular Symposia, 163, 135-143 (2001). https://doi.org/10.1002/1521-3900(200101)163:1<135::AIDMASY $135>3.0 . C O ; 2-7$

[7] Kurelec L., Teeuwen M., Schoffeleers H., Deblieck R.: Strain hardening modulus as a measure of environmental stress crack resistance of high density polyethylene. Polymer, 46, 6369-6379 (2005).

https://doi.org/10.1016/j.polymer.2005.05.061

[8] Chen Y., Lei Y., Zou H., Liang M., Cao Y.: Structural and rheological property relationship of bimodal polyethylene with improved environment stress cracking resistance. Polymer Science Series A, 56, 671-680 (2014). https://doi.org/10.1134/S0965545X14050058

[9] Cheng J. J., Polak M. A., Penlidis A.: A tensile strain hardening test indicator of environmental stress cracking resistance. Journal of Macromolecular Science Part A: Pure and Applied Chemistry, 45, 599-611 (2008). https://doi.org/10.1080/10601320802168728 
[10] Cardoso M. N., Fisch A. G.: Bimodal high-density polyethylene: Influence of the stereoregularity of the copolymer fraction on the environmental stress crack resistance. Industrial and Engineering Chemistry Research, 55, 6405-6412 (2016).

https://doi.org/10.1021/acs.iecr.6b00927

[11] Sun X., Shen H., Xie B., Yang W., Yang M.: Fracture behavior of bimodal polyethylene: Effect of molecular weight distribution characteristics. Polymer, 52, 564 570 (2011).

https://doi.org/10.1016/j.polymer.2010.12.008

[12] Gulmine J. V., Janissek P. R., Heise H. M., Akcelrud L.: Degradation profile of polyethylene after artificial accelerated weathering. Polymer Degradation and Stability, 79, 385-397 (2003). https://doi.org/10.1016/S0141-3910(02)00338-5

[13] Grigoriadou I., Paraskevopoulos K. M., Chrissafis K., Pavlidou E., Stamkopoulos T-G., Bikiaris D.: Effect of different nanoparticles on HDPE UV stability. Polymer Degradation and Stability, 96, 151-163 (2011). https://doi.org/10.1016/j.polymdegradstab.2010.10.001

[14] Feldman D.: Polymer weathering: Photo-oxidation. Journal of Polymers and the Environment, 10, 163-173 (2002).

https://doi.org/10.1023/A:1021148205366

[15] Wang M-J., Gray C. A., Reznek S. R., Mahmud K., Kutsovsky Y.: Carbon black in 'Encyclopedia of polymer science and technology' (eds.: Mark H. F., Bikales N. M.) Wiley, Hoboken, Vol 9, 52-91 (2003). https://doi.org/10.1002/0471440264.pst477

[16] Liu M., Horrocks A. R.: Effect of carbon black on UV stability of LLDPE films under artificial weathering conditions. Polymer Degradation and Stability, 75, 485499 (2002).

https://doi.org/10.1016/S0141-3910(01)00252-X

[17] Williams J. C.: The mixing of dry powders. Powder Technology, 2, 13-20 (1968). https://doi.org/10.1016/0032-5910(68)80028-2

[18] Fan L. T., Chen S. J., Watson C. A.: Annual review solids mixing. Industrial and Engineering Chemistry, 62, 5369 (1970).

https://doi.org/10.1021/ie50727a009

[19] Ottino J. M., Khakhar D. V.: Mixing and segregation of granular materials. Annual Review of Fluid Mechanics, 32, 55-91 (2000).

https://doi.org/10.1146/annurev.fluid.32.1.55

[20] Pierre S., Thielen A., Cammarata D.: High loading carbon black masterbatch for pressure pipe applications. U.S. Patent 20120108725 A1, USA (2012).

[21] Deveci S., Buryak A., Motha K., Kumar A., Äärilä J., Martin S., Hristov V., Bergman N.: Polymer composition comprising carbon black and a carrier polymer for the carbon black. EP 2889323 A1, EU (2015).

[22] Eslamian M., Bagheri R., Pircheraghi G.: Co-crystallization in ternary polyethylene blends: Tie crystal formation and mechanical properties improvement. Polymer International, 65, 1405-1416 (2016).

https://doi.org/10.1002/pi.5191
[23] Xu J., Xu X., Chen L., Feng L., Chen W.: Effect of composition distribution on miscibility and co-crystallization phenomena in the blends of low density polyethylene with conventional and metallocene-based ethylene-butene copolymers. Polymer, 42, 3867-3874 (2001). https://doi.org/10.1016/S0032-3861(00)00756-4

[24] Cho K., Lee B. H., Hwang K-M., Lee H., Choe S.: Rheological and mechanical properties in polyethylene blends. Polymer Engineering and Science, 38, 19691975 (1998). https://doi.org/10.1002/pen.10366

[25] Hussein I. A.: Influence of composition distribution and branch content on the miscibility of m-LLDPE and HDPE blends: Rheological investigation. Macromolecules, 36, 2024-2031 (2003).

https://doi.org/10.1021/MA0257245

[26] Dealy J. M., Wissbrun K. F.: Melt rheology and its role in plastics processing-theory and appications. Springer, Dordrecht (1990).

https://doi.org/10.1007/978-94-009-2163-4

[27] Li Pi Shan C., Soares J. B. P., Penlidis A.: HDPE/ LLDPE reactor blends with bimodal microstructures Part I: Mechanical properties. Polymer, 43, 7345-7365 (2002).

https://doi.org/10.1016/S0032-3861(02)00703-6

[28] García R. A., Carrero A., Martín C., Domínguez C.: Effects of the structural components on slow crack growth process in polyethylene blends. Composition intervals prediction for pipe applications. Journal of Applied Polymer Science, 121, 3269-3276 (2011).

https://doi.org/10.1002/app.33911

[29] Cheng J. J., Polak M. A., Penlidis A.: Influence of micromolecular structure on environmental stress cracking resistance of high density polyethylene. Tunnelling and Underground Space Technology, 26, 582-593 (2011). https://doi.org/10.1016/j.tust.2011.02.003

[30] Pan Y., Gao X., Wang Z., Lei J., Li Z., Shen K.: Effect of different morphologies on slow crack growth of highdensity polyethylene. RSC Advances, 5, 28191-28202 (2015). https://doi.org/10.1039/C5RA00918A

[31] Zhou H., Wilkes G. L.: Comparison of lamellar thickness and its distribution determined from d.s.c., SAXS, TEM and AFM for high-density polyethylene films having a stacked lamellar morphology. Polymer, 38, 5735-5747 (1997). https://doi.org/10.1016/S0032-3861(97)00145-6

[32] Fawaz J., Deveci S., Mittal V.: Molecular and morphological studies to understand slow crack growth (SCG) of polyethylene. Colloid and Polymer Science, 294, 1269-1280 (2016). https://doi.org/10.1007/s00396-016-3888-5

[33] Chen Y., Zou H., Liang M., Liu P.: Study on the dynamic rheological behavior of four different bimodal polyethylenes. Journal of Macromolecular Science Part B: Physics, 52, 924-936 (2013). https://doi.org/10.1080/00222348.2012.746554 
[34] Chen Y., Luo W., Li Y., Zou H., Liang M., Cao Y.: Melt flow instabilities in polyethylene resins. Polymer Science Series A, 56, 662-670 (2014). https://doi.org/10.1134/S0965545X1405006X

[35] Mieda N., Yamaguchi M.: Flow instability for binary blends of linear polyethylene and long-chain branched polyethylene. Journal of Non-Newtonian Fluid Mechanics, 166, 231-240 (2011).

https://doi.org/10.1016/j.jnnfm.2010.11.011

[36] Osswald T., Rudolph N.: Polymer rheology. Hanser, München (2014).

https://doi.org/10.3139/9781569905234

[37] van Melick H. G. H., Govaert L. E., Meijer H. E. H.: On the origin of strain hardening in glassy polymers. Polymer, 44, 2493-2502 (2003).

https://doi.org/10.1016/S0032-3861(03)00112-5
[38] Tian Z., Chen K-R., Liu B-P., Luo N., Du W-L., Qian F.: Short-chain branching distribution oriented model development for Borstar bimodal polyethylene process and its correlation with product performance of slow crack growth. Chemical Engineering Science, 130, 4155 (2015).

https://doi.org/10.1016/j.ces.2015.03.001

[39] Munaro M., Akcelrud L.: Polyethylene blends: A correlation study between morphology and environmental resistance. Polymer Degradation and Stability, 93, 4349 (2008). https://doi.org/10.1016/j.polymdegradstab.2007.10.017

[40] Adib A., Domínguez C., García R. A., Garrido M. A., Rodríguez J.: Influence of specimen geometry on the slow crack growth testing of HDPE for pipe applications. Polymer Testing, 48, 104-110 (2015). https://doi.org/10.1016/j.polymertesting.2015.09.012 